\title{
FIM DA COMPULSORIEDADE DA CONTRIBUIÇÃO SINDICAL: REFORMA TRABALHISTA E MEDIDA PROVISÓRIA 873/2019
}

\author{
Fabricio Santos Müzel de Moura *
}

\section{RESUMO}

A Lei 13.467/2017 condicionou recolhimento da contribuição sindical, antes obrigatório, à autorização prévia e expressa do empregado. A nova lei não vedou a deliberação coletiva da categoria para tal autorização, prática referendada pelo Tribunal Superior do Trabalho e Ministério Público do Trabalho. Contudo, a Medida Provisória 873/2019 restringiu o recolhimento à autorização prévia, expressa, por escrito, individual e mediante boleto bancário, vendando o desconto em folha. No presente trabalho discute-se a viabilidade da autorização ao recolhimento da contribuição sindical de forma coletiva e a constitucionalidade da MP 873/2019 sob o prisma do princípio da liberdade sindical e da autonomia sindical.

Palavras-chave: Contribuição sindical, reforma trabalhista, autorização coletiva, liberdade sindical.

\section{END OF COMPULSORY OF UNION CONTRIBUTION: LABOR REFORM AND PROVISIONAL MEASURE 873/2019}

\begin{abstract}
Law $13.467 / 2017$ conditioned the payment of union contribution, previously compulsory, to the prior and express authorization of employees. The new law did not prohibit the collective deliberation of the category for such authorization, a practice endorsed by the Superior Labor Court and the Labor Prosecution Office. However, Provisional Measure 873/2019 restricted the collection to prior authorization, expressed, in writing, individually and by bank-slip, prohibiting payroll deduction. This paper discusses the feasibility of the authorization to collect the union contribution collectively and the constitutionality of PM 873/2019 under the prism of the principle of freedom of association and union autonomy.
\end{abstract}

Keywords: union contribution, labor law reform, collective permission, freedom of association.

\section{INTRODUÇÃO}

No ano de 2017, a Consolidação das Leis do Trabalho sofreu a mais profunda alteração legislativa desde a sua criação. Por intermédio da Lei 13.367/2017, mais de cem

\footnotetext{
* Especialista em Direito Coletivo do Trabalho pelo Instituto Euvaldo Lodi (2018). Graduado pela Universidade Federal do Paraná (2011). Atualmente ocupa o cargo de advogado na Companhia de Habitação do Paraná COHAPAR.
} 
artigos da CLT foram modificados, sendo uma das mais significativas a retirada da compulsoriedade da contribuição sindical.

Anteriormente obrigatória, a contribuição sindical passou a ter o seu recolhimento condicionado à autorização prévia e expressa dos empregados e, no caso da contribuição sindical devida pelos empregadores, ao exercício de tal opção pelo empresário no mês de janeiro de cada ano.

Ao mesmo tempo em que a Lei 13.467/2017 conferiu grande responsabilidade e importância aos sindicatos, dando prevalência aos instrumentos negociais coletivos sobre o texto de $\mathrm{lei}^{2}$, alterou sensivelmente a principal fonte de custeio das entidades sindicais.

Como reação à alteração legislativa, discutiu-se a possibilidade de realização da autorização prévia ao desconto de forma coletiva, em assembleias realizadas pelas entidades sindicais. A prática começou a ser aceita e homologada por algumas decisões judiciais, garantindo até mesmo o exercício do direito de oposição para empregados não sindicalizados.

Contudo, em que pese a reforma trabalhista tenha até mesmo cunhado o termo "princípio da intervenção mínima na autonomia da vontade coletiva"3, a Medida Provisória 873 de 01.02.2019 trouxe mais obstáculos ao financiamento das entidades sindicais.

O presente artigo tem por objetivo analisar as alterações provocadas pela Lei 13.467/2017 no âmbito da regulamentação do sistema de custeio das entidades sindicais. Em seguida, pretende-se discutir sobre a viabilidade da autorização coletiva para desconto da contribuição sindical mediante revisão bibliográfica e estudo da jurisprudência pátria bem como de decisões proferidas pelo Comitê de Liberdade Sindical da OIT. Por fim, debate-se a constitucionalidade das alterações promovidas na CLT pela MP 873/2019 com enfoque nos princípios da autonomia e liberdade sindical.

\section{LEI 13.467/2017: O FIM DA OBRIGATORIEDADE DA CONTRIBUIÇÃO SINDICAL}

\footnotetext{
${ }^{2}$ A Lei 13.467/2017 inseriu o art. 611-A cujo caput tem a seguinte redação: "Art. 611-A. A convenção coletiva e o acordo coletivo de trabalho, observados os incisos III e VI do caput do art. $8^{\circ}$ da Constituição, têm prevalência sobre a lei quando, entre outros, dispuserem sobre: (...)". Em virtude da expressão "entre outros", denota-se um rol aberto de possibilidades de negociação coletiva desde que não haja vedação legal ou contrariedade à Constituição da República.

${ }^{3}$ Art. $8^{\circ}, \S 3^{\circ}$ da CLT: "No exame de convenção coletiva ou acordo coletivo de trabalho, a Justiça do Trabalho analisará exclusivamente a conformidade dos elementos essenciais do negócio jurídico, respeitado o disposto no art. 104 da Lei no 10.406, de 10 de janeiro de 2002 (Código Civil), e balizará sua atuação pelo princípio da intervenção mínima na autonomia da vontade coletiva."
} 
Conforme classificação de Brito Filho (2012, p. 128-133), as contribuições destinadas ao custeio das entidades sindicais seriam quatro: 1) contribuição social; 2) contribuição sindical; 3) contribuição confederativa e 4) contribuição assistencial.

De acordo com a lição do doutrinador, a contribuição social, ou mensalidade sindical, corolário lógico do direito de associação ou de filiação, é cobrada periodicamente dos empregados sindicalizados. A contribuição sindical é aquela que, até a entrada em vigor da reforma trabalhista em 2017, possuía natureza compulsória, cobrada tanto de sindicalizados quanto de não sindicalizados. A contribuição confederativa é prevista no art. $8^{\circ}$, IV da CF, que pode ou não ser instituída, a depender de decisão tomada pela assembleia geral do sindicato, razão pela qual seria exigível apenas dos associados. Por fim, a contribuição assistencial, também conhecida como desconto assistencial, taxa de fortalecimento sindical ou taxa sindical, normalmente é cobrada para o custeio de despesas de campanha das entidades sindicais após o estabelecimento de negociações coletivas. (BRITO FILHO, 2012, p. 128-133).

A Constituição da República, no inciso IV do art. $8^{\circ}$, dispõe que " a assembleia geral fixará a contribuição que, em se tratando de categoria profissional, será descontada em folha, para custeio do sistema confederativo da representação sindical respectiva, independentemente da contribuição prevista em lei”.

Antes da vigência da Lei 13.467/2017, o art. 545 da CLT dispunha que os empregadores eram obrigados a descontar na folha de pagamento de seus empregados, desde que devidamente autorizados, as contribuições devidas ao Sindicato, quando por este notificados, exceto quanto à contribuição sindical, cujo desconto independia de tal formalidade. Por sua vez, o art. 579 determinava que a contribuição sindical era devida por todos aqueles que participassem de determinada categoria econômica ou profissional, ou de profissão liberal, em favor do sindicato representativo da mesma categoria ou profissão.

Até então, um marcante elemento distintivo entre a contribuição sindical e as demais fontes de custeio do sistema sindical era a característica da compulsoriedade, de modo que poderia ser descontada mesmo de empregados não filiados a entidades sindicais. Antes da reforma trabalhista, compreendia-se que a contribuição sindical envolve obrigação de prestação pecuniária de natureza compulsória, uma vez que o seu recolhimento não dependia 
do interesse do empregado ou empregador em contribuir com o sindicato. (MARTINS, 2009, p. 44-45).

No mesmo sentido, Silva Martins (2015, p. 95) ensinou que a contribuição sindical “(...) objetiva garantir a existência dos movimentos sindicais de trabalhadores e patronais, sendo, na dicção do art. $8^{\circ}$, inciso IV, a exata razão de sua exigência como perfil de natureza tributária".

Anteriormente obrigatória, a contribuição sindical passou a ter o seu recolhimento condicionado à autorização prévia e expressa dos empregados e, no caso da contribuição sindical devida pelos empregadores, ao exercício de tal opção pelo empresário no mês de janeiro de cada ano. Ou seja, a compulsoriedade deixou de caracterizar a contribuição sindical, que também passou a depender da autorização dos trabalhadores envolvidos bem como dos empregadores no caso da quota patronal ${ }^{4}$.

Tendo em vista que as alterações na legislação trabalhista deram-se apenas por intermédio de lei ordinária, não seria possível extinguir a contribuição sindical prevista no inciso IV do art. $8^{\circ}$ da Constituição da República. Optou-se, portanto, em trocar a obrigatoriedade no recolhimento da contribuição sindical pela sua facultatividade nos artigos 545, 578, 579, 582, 583, 587 e 602 da CLT.

No relatório emitido pelo Deputado Rogério Marinho, integrante da Comissão Especial instituída na Câmara dos Deputados para proferir parecer sobre o Projeto de Lei 6.787/2016, convertido na Lei 13.467/2017, a intenção foi clara no sentido de instituir a faculdade em recolher a contribuição sindical, de maneira que apenas o empregado sindicalizado efetuasse o seu pagamento quando outorgasse autorização prévia e expressa:

\begin{abstract}
A existência de uma contribuição de natureza obrigatória explica, em muito, o número de sindicatos com registro ativo existentes no País. Até março de 2017, eram 11.326 sindicatos de trabalhadores e 5.186 sindicatos de empregadores, segundo dados obtidos no Cadastro Nacional de Entidades Sindicais do Ministério do Trabalho. (...) Somente no ano de 2016, a arrecadação da contribuição sindical alcançou a cifra de $\mathrm{R} \$ 3,96$ bilhões de reais.
\end{abstract}

\footnotetext{
${ }^{4}$ Art. 579. $\quad$ O desconto da contribuição sindical está condicionado à autorização prévia e expressa dos que participarem de uma determinada categoria econômica ou profissional, ou de uma profissão liberal, em favor do sindicato representativo da mesma categoria ou profissão ou, inexistindo este, na conformidade do disposto no art. 591 desta Consolidação.

Art. 545. Os empregadores ficam obrigados a descontar da folha de pagamento dos seus empregados, desde que por eles devidamente autorizados, as contribuições devidas ao sindicato, quando por este notificados.
} 
Os sindicatos, sejam eles classistas ou patronais, não mais poderão ficar inertes, sem buscar resultados efetivos para as suas respectivas categorias, respaldados em uma fonte que não seca, que eles recebem independentemente de apresentarem quaisquer resultados. Aqueles que se sentirem efetivamente representados por seus sindicatos, trabalhadores ou empregadores, pagarão suas contribuições em face dos resultados apresentados. Os que não tiverem resultados a apresentar, aqueles que forem meros sindicatos de fachada, criados unicamente com o objetivo de arrecadar a contribuição obrigatória, esses estarão fadados ao esquecimento.

O ideal, a nosso ver, era que a contribuição sindical ficasse restrita aos trabalhadores e empregadores sindicalizados (...) (BRASIL, 2017, p. 28-29)

Justificou-se a alteração legislativa sob o argumento de que traria fortalecimento para os sindicatos que representam, de fato, sua categoria. Segundo o relatório da comissão, o fim da compulsoriedade do recolhimento do tributo provocaria, naturalmente, o fim das entidades sindicais de fachada, criadas apenas para obter a receita de arrecadação da contribuição sindical.

No entanto, o dever das entidades sindicais de prestar assistência a toda a categoria permaneceu inalterado. Igualmente, os instrumentos de negociação coletiva continuaram surtindo efeitos para todos os empregados, sejam sindicalizados ou não, uma vez que restaram incólumes os institutos da unicidade sindical (art. $8^{\circ}$, II da CF), representatividade compulsória (art. $8^{\circ}$, III, da CF) e contribuição sindical (art. $8^{\circ}$, IV, parte final, da CF).

A autorização prévia para recolhimento da contribuição sindical conferida pelos empregados de forma coletiva, por meio de assembleia, surgiu, portanto, como alternativa para a sobrevivência financeira, haja vista que se funda em dispositivos legais e constitucionais intocados, até então, pela reforma trabalhista. A rapidez com que tramitou o projeto de lei e a falta de debate profundo acerca das alterações legislativas pretendidas deixaram um vasto terreno de alternativas hermenêuticas para se buscar a sobrevivência financeira das entidades sindicais.

\section{AUTORIZAÇÃo COLETIVA PARA DESCONTO DA CONTRIBUiÇÃo SINDICAL}


Sendo os sindicatos entidades que representam uma coletividade de trabalhadores, conforme art. $8^{\circ}$, III da Constituição da República ${ }^{5}$, natural que uma das soluções encontradas para obter a autorização de empregados tenha se dado por intermédio da realização de assembleias gerais na forma dos estatutos dos sindicatos.

A alínea "e" do art. 513 da CLT, dispositivo não modificado pela Lei 13.467/2017, consigna como prerrogativa dos sindicatos a imposição de contribuições a todos aqueles que compõem as categorias econômicas ou profissionais ou das profissões liberais representadas.

Se a nova redação dos dispositivos relacionados à contribuição sindical condicionou o seu recolhimento à autorização prévia dos empregados, defendeu-se a possibilidade de conferir tal autorização de forma coletiva, mediante deliberação realizada em assembleia geral do sindicato convocada para tal fim na forma de seu estatuto. Tal interpretação gerou intenso debate doutrinário conforme se passa expor adiante.

Em outubro de 2017, a Associação Nacional dos Magistrados da Justiça do Trabalho (ANAMATRA) divulgou 125 enunciados aprovados na $2^{\text {a }}$ Jornada de Direito Material e Processual do Trabalho. Dentre os enunciados, relevante para o tema sob análise o verbete de número 38:

38. CONTRIBUIÇÃO SINDICAL

I - É LÍCITA A AUTORIZAÇÃO COLETIVA PRÉVIA E EXPRESSA PARA O DESCONTO DAS CONTRIBUIÇÕES SINDICAL E ASSISTENCIAL, MEDIANTE ASSEMBLEIA GERAL, NOS TERMOS DO ESTATUTO, SE OBTIDA MEDIANTE CONVOCAÇÃO DE TODA A CATEGORIA REPRESENTADA ESPECIFICAMENTE PARA ESSE FIM, INDEPENDENTEMENTE DE ASSOCIAÇÃO E SINDICALIZAÇÃO.

II - A DECISÃO DA ASSEMBLEIA GERAL SERÁ OBRIGATÓRIA PARA TODA A CATEGORIA, NO CASO DAS CONVENÇÕES COLETIVAS, OU PARA TODOS OS EMPREGADOS DAS EMPRESAS SIGNATÁRIAS DO ACORDO COLETIVO DE TRABALHO.

III - O PODER DE CONTROLE DO EMPREGADOR SOBRE O DESCONTO DA CONTRIBUIÇÃO SINDICAL É INCOMPATÍVEL COM O CAPUT DO ART. $8^{\circ}$ DA CONSTITUIÇÃO FEDERAL E COM O ART. $1^{\circ}$ DA CONVENÇÃO 98 DA OIT, POR VIOLAR OS PRINCÍPIOS DA LIBERDADE E DA AUTONOMIA

\footnotetext{
${ }^{5}$ III - ao sindicato cabe a defesa dos direitos e interesses coletivos ou individuais da categoria, inclusive em questões judiciais ou administrativas;
} 
SINDICAL E DA COIBIÇÃO AOS ATOS ANTISSINDICAIS. (ANAMATRA, 2017)

Conforme entendimento da referida associação de magistrados, seria plenamente viável a autorização coletiva prévia e expressa, mediante deliberação em assembleia geral. O referido enunciado foi elaborado a partir das teses da Comissão Temática de $\mathrm{n}^{\mathrm{o}}$. 3, relacionadas à análise das mudanças da Lei 13.467/2017 no Direito Coletivo do Trabalho.

Segundo os estudos da referida Comissão Temática, a sistemática de condicionar o recolhimento da contribuição sindical à autorização prévia e expressa do empregado contribui para a prática de atos antissindicais em afronta o princípio da liberdade sindical insculpido no art. $8^{\circ}$ da Constituição da República bem como a Convenção nº 98 da OIT. Assim, alertou-se que a identificação individual do empregado no momento em que autoriza o desconto da contribuição sindical facilitaria a prática de atos antissindicais por parte do empregador como, por exemplo, a perseguição daqueles empregados que, mesmo não sendo sindicalizados, optaram por contribuir para o sindicato de sua categoria quando a contribuição deixou de ser compulsória.

Conforme entendimento da ANAMATRA, a facultatividade no recolhimento da contribuição sindical seria, portanto, incompatível com art. $8^{\circ}$ da Constituição da República e com a Convenção 98 da OIT, da qual o Brasil é signatário.

O Ministério do Trabalho e Emprego foi questionado sobre a matéria pela Federação Interestadual dos Trabalhadores Hoteleiros, e, em resposta, a Secretaria das Relações de Trabalho expediu a Nota Técnica $\mathrm{n}^{\circ}$. 02/2018/GAB/SRT, acompanhando o entendimento da ANAMATRA e concluindo que, a partir de uma interpretação sistemática do ordenamento jurídico, é possível firmar o entendimento de que a anuência prévia e expressa dos empregados pode ser consumada a partir da vontade da categoria estabelecida em assembleia geral $^{6}$. (LACERDA, 2018).

Já o Ministério Público do Trabalho, por intermédio da Nota Técnica $\mathrm{n}^{\circ}$. 01 de 27.04.2018 da Coordenadoria Nacional de Promoção da Liberdade Sindical (CONALIS), consolidou entendimento de que a autorização prévia e expressa sequer poderia se dar de forma individual, mas tão somente de forma coletiva. De acordo com a nota técnica, não seria

\footnotetext{
6 Nota Técnica $\mathrm{n}^{\text {o. }}$ 02/2018 da Secretaria de Relações do Trabalho do MTE. Disponível em: <http://www.fnn.org.br/Noticias/582>. Acesso em: 01 abr.2019.
} 
constitucional, adequado ou razoável interpretar que a autorização prévia e expressa possa ser individual, pois historicamente a supervalorização do individualismo não contribui para a construção de uma sociedade livre, justa e solidária, um dos objetivos da República insculpidos no art. $3^{\circ}$ da CF. (VALENTIM e OLIVEIRA NETO, 2018)

No entanto, o entendimento jurisprudencial consolidado pelo Tribunal Superior do Trabalho e reafirmado pelo Supremo Tribunal Federal, antes da vigência da Lei 13.467/2017, era diverso.

Diante do arcabouço legal pretérito que conferiu a compulsoriedade apenas para o recolhimento da contribuição sindical, houve grande debate jurisprudencial acerca da possibilidade de instituição e cobrança das demais contribuições sindicais para empregados não sindicalizados.

Anteriormente à vigência da Lei 13.467/2017, o posicionamento consolidado pelo TST era contrário ao desconto de contribuição fixada em assembleia da categoria ou em negociação coletiva para empregado não sindicalizado.

A Orientação Jurisprudencial nº 17 da Seção de Dissídios Coletivos (SDC) do TST consolidou entendimento de que as cláusulas coletivas que estabelecessem contribuição em favor de entidade sindical para empregados não sindicalizados seriam atentatórias ao direito de livre associação e livre sindicalização.

Em semelhante sentido, o Precedente Normativo n ${ }^{\circ} .119$ da SDC do TST considerou contrário ao direito de livre associação e sindicalização o estabelecimento, por cláusula negocial coletiva, de contribuição em favor da entidade sindical a título de taxa para custeio do sistema confederativo, assistencial, revigoramento ou fortalecimento sindical e outras da mesma espécie, obrigando trabalhadores não sindicalizados.

O Sindicato dos Metalúrgicos de Curitiba questionou a constitucionalidade de tal entendimento, que foi, por sua vez, reafirmado pelo Supremo Tribunal Federal no ARE 1018459, em março de 2017:

Recurso Extraordinário. Repercussão Geral. 2. Acordos e convenções coletivas de trabalho. Imposição de contribuições assistenciais compulsórias descontadas de empregados não filiados ao sindicato respectivo. Impossibilidade. Natureza não tributária da contribuição. Violação ao princípio da legalidade tributária. Precedentes. 3. Recurso extraordinário não provido. Reafirmação de jurisprudência da Corte. (ARE 1018459 RG, Relator(a): Min. GILMAR MENDES, julgado em 
23/02/2017, PROCESSO ELETRÔNICO REPERCUSSÃO GERAL - MÉRITO DJe-046 DIVULG 09-03-2017 PUBLIC 10-03-2017)

Em que pese se defenda que a impossibilidade de se cobrar contribuições sindicais instituídas por deliberação coletiva de empregados não sindicalizados seja a salvaguarda do direito de livre associação e livre sindicalização, tal assertiva é questionável quando o ordenamento jurídico autoriza a aplicação de cláusulas negociais coletivas, de forma erga omnes, para empregados sindicalizados ou não.

Delgado (2018) afirma que a diretriz da jurisprudência majoritária consolidada pelo TST e pelo STF não prestigia os princípios da liberdade sindical e da autonomia dos sindicatos. Ao contrário do que se sustenta, para Delgado, o entendimento jurisprudencial predominante aponta restrição incomum no contexto do sindicalismo dos países ocidentais com experiência democrática consolidada. Ainda, o doutrinador assevera que o posicionamento da jurisprudência não se amolda à lógica do sistema constitucional e à melhor interpretação dos princípios da liberdade e autonomia sindical na estrutura da Constituição da República:

É que, pelo sistema constitucional trabalhista no Brasil, a negociação coletiva sindical favorece a todos os trabalhadores integrantes da correspondente base sindical, independentemente de serem (ou não) filiados ao respectivo sindicato profissional. Dessa maneira, torna-se proporcional, equânime e justo (além de manifestamente legal: texto expresso do art. 513, "e", da CLT) que esses trabalhadores também contribuam para a dinâmica da negociação coletiva trabalhista, mediante a cota de solidariedade estabelecida no instrumento coletivo. Aliás, por isso mesmo a verba é apelidada também de cota de solidariedade. (DELGADO, 2018, p. 1.600)

Ainda assim, Delgado reconhece que a Lei 13.467/2017 veio proibir, de modo expresso, a cobrança da contribuição sindical, ou de qualquer outra contribuição de caráter e destino sindical, sem a prévia e expressa anuência do trabalhador. $\mathrm{O}$ doutrinador entende que, não havendo estipulação de montante abusivo, não haveria por que se negar validade a instrumento de negociação coletiva que contemple a possibilidade de insurgência individual do trabalhador, de forma simples e acessível, em face da deliberação coletiva. Contudo, conclui que esta não é a tônica dos entendimentos da OJ n ${ }^{\circ} .17$ e Precedente Normativo $n^{\circ}$. 
119 da SDC do TST e, muito menos, desde a Lei a13.467/2017, a mens legis do art. 611-B, XXVI da CLT $^{7}$. (DELGADO, 2018, p. 1.600-1.601)

Importante salientar que, inicialmente, até mesmo a OIT se mostrou contrária às contribuições sindicais impostas de forma compulsória por entender que afrontavam ao princípio da liberdade sindical. Nesse sentido, a decisão de $n^{\circ}$. 434 do Comitê de Liberdade Sindical da OIT de 1996:

434. As questões relativas ao financiamento das organizações sindicais e de empregadores, tanto no que diz respeito a seus próprios orçamentos como aos das federações e confederações, deveriam regular-se pelos estatutos dos sindicatos, das federações e confederações, razão pela qual a imposição de contribuições por meio da Constituição ou por via legal não é conforme os princípios da liberdade sindical. (OIT, 2013, p. 98)

No entanto, segundo a escólio de Arouca (2016), o posicionamento da OIT evoluiu para reconhecer a possibilidade de desconto nos salários, mesmo dos empregados não sindicalizados, quando toda a categoria se beneficiasse de instrumentos de negociação coletiva. Tal entendimento, segundo o autor, é compartilhado pela legislação de países como Argentina, Alemanha, Honduras, Colômbia, Equador, Panamá e Suíça. Arouca cita valiosa lição de Arnaldo Lopes Süssekind ${ }^{8}$ sobre o direito comparado:

O que o Comitê (de Liberdade Sindical) vem admitindo, para reforçar as finanças do sindicato é a estipulação de uma quota de solidariedade, ou cânon de participação, na convenção coletiva por ele ajustada, como decorrência da aplicação erga omnes, de vantagens estabelecidas no instrumento negociado ou arbitrado, a ser pago exclusivamente pelos não associados. A cobrança dessa quota ou cânon vem-se generalizando. Argentina, Colômbia, Espanha, Grécia e Reino Unido já a adotaram, exigindo-a dos não associados beneficiados pela negociação ou arbitragem. Na Suíça e na Turquia as condições ajustadas ou arbitradas não se aplicam erga omnes, só beneficiando os não associados que pagarem essa quota correspondente ao sindicato. Segundo revelam publicações da OIT, outro sistema foi adotado na

\footnotetext{
${ }^{7}$ Art. 611-B. Constituem objeto ilícito de convenção coletiva ou de acordo coletivo de trabalho, exclusivamente, a supressão ou a redução dos seguintes direitos: (...)

XXVI - liberdade de associação profissional ou sindical do trabalhador, inclusive o direito de não sofrer, sem sua expressa e prévia anuência, qualquer cobrança ou desconto salarial estabelecidos em convenção coletiva ou acordo coletivo de trabalho;

${ }^{8}$ SÜSSEKIND, A. L. Comentários à Constituição. Rio de Janeiro: Freitas Bastos, v. II, 1991. p. 48.
} 
República Árabe da Síria, no Panamá e na Tanzânia, onde os trabalhadores não sindicalizados estão obrigados, independentemente da atuação do sindicato da respectiva categoria ou empresa, a pagar-lhe uma contribuição, se metade dos componentes do grupo representado pertencer ao seu quadro de associados. (SÜSSEKIND, 1991 apud AROUCA, 2016, p. 168)

O ementário do Comitê de Liberdade Sindical da OIT contempla decisões quanto ao tema que alimentam de forma construtiva o debate sobre o atual modelo de custeio do sistema sindical criado pela Lei 13.467/2017:

474. Dever-se-ia evitar a proibição do desconto em folha das contribuições, que pudesse causar dificuldades financeiras para organizações sindicais, pois não propicia o desenvolvimento de harmoniosas relações profissionais.

480. Quando uma legislação aceita cláusulas de segurança sindical, como a dedução de contribuições sindicais de não filiados que se beneficiam da contratação coletiva, tais cláusulas só deveriam se tornar efetivas por meio das convenções coletivas.

481. A questão do desconto de contribuições sindicais pelos empregadores e seu repasse para os sindicatos deve ser resolvida pela negociação coletiva entre empregadores e sindicatos em geral, sem obstáculos de natureza legislativa. (OIT, 2013, p. 124-125)

Quanto à decisão $n^{\circ} .474$ acima transcrita, verifica-se a recomendação do Comitê de Liberdade Sindical na OIT no sentido de se evitar a proibição do desconto em folha de contribuições que seja capaz de causar dificuldades financeiras para organizações sindicais. De outra banda, a modificação abrupta conferida pela Lei 13.467/2017, com a retirada da compulsoriedade da contribuição sindical, e posteriormente, com o endurecimento das regras de recolhimento da contribuição sindical pela Medida Provisória 873/2019, quedou-se atingida a principal fonte de custeio das entidades sindicais ${ }^{9}$.

Conforme decisão de $\mathrm{n}^{\mathrm{o}}$. 480 do Comitê de Liberdade Sindical da OIT, se o ordenamento jurídico de um país permite o desconto de contribuições sindicais de empregados não filiados que se beneficiam de negociação coletiva, tais cláusulas apenas

\footnotetext{
${ }^{9}$ Segundo ensinamento de Brito Filho (2012, p. 129), a contribuição sindical é a mais importante no Brasil, pois temos uma tendência de antipatia à contribuição social (ou mensalidade sindical) tanto por parte dos empregados quanto por parte das entidades Sindicais. Segundo o autor, no modelo de unicidade sindical, a única resistência que pode ser oferecida é interna. Logo, quanto mais sócios o sindicato tiver, maior a possibilidade de resistência e alternância de poder. Assim, a maioria dos sindicatos prefere distribuir o ônus de custear as entidades sindicais com os não associados ou "optar" que o custeio venha somente de não associados por intermédio da contribuição sindical.
} 
deveriam se tornar efetivas por meio de negociação coletiva. Seguindo a mesma linha de raciocínio, a decisão de $\mathrm{n}^{\mathrm{o}}$. 480 consigna o entendimento de que a questão do desconto das contribuições sindicais pelos empregadores e seu repasse aos sindicatos deve ser objeto de negociação coletiva, sem obstáculos de natureza legal.

Em sentido diametralmente oposto do entendimento da OIT, o art. 611-B, XXVI da CLT, inserido pela Lei 13.467/2017, considera objeto ilícito de instrumentos de negociação coletiva a disposição que altere o direito de não sofrer, sem sua expressa e prévia anuência, qualquer cobrança ou desconto salarial estabelecidos em convenção coletiva ou acordo coletivo de trabalho.

O fim da compulsoriedade da contribuição sindical foi objeto da Ação Direta de Inconstitucionalidade $\mathrm{n}^{\mathrm{o}}$. 5794, bem como de outras dezoito ações diretas de inconstitucionalidade, além de uma Ação Declaratória de Constitucionalidade (ADC). Tais demandas foram julgadas pelo STF nos dias 28 e 29 de junho de 2018.

A ADI 5794, ajuizada pela Confederação Nacional dos Trabalhadores em Transporte Aquaviário e Aéreo, na Pesca e nos Portos, (CONTTMAF), teve por objeto o art. $1^{\circ}$ da Lei 13.467/2017 que conferiu nova redação aos artigos 545, 578, 579, 582, 583, 587 e 602 da CLT.

A CONTTMAF arguiu a inconstitucionalidade das alterações legislativas por afronta aos 146, II e III, 149 e 150, $§ 6^{\circ}$, da CF, defendendo a necessidade de lei complementar específica para promover alterações na regulamentação da contribuição sindical. Aduziu-se que Lei 13.467/2017 desrespeitou direitos e garantias fundamentais dos trabalhadores e que o dever de prestar assistência sindical aos trabalhadores ficaria comprometido sem a principal fonte de custeio.

O ministro relator, Edson Fachin, pontuou em seu voto que o regime sindical estabelecido pela Constituição de 1988 sustenta-se por três pilares fundamentais: a unicidade sindical (art. $8^{\circ}$, II da CF), representatividade compulsória (art. $8^{\circ}$, III, da CF) e contribuição sindical (art. $8^{\circ}$, IV, parte final, da CF). Por tal motivo, ponderou que a modificação de apenas desses pilares pode desestabilizar todo o sistema sindical, na medida em que as entidades sindicais seriam obrigadas a representar até mesmo aqueles que com ela não mantém um vínculo contributivo.

No entanto, o entendimento prevalecente foi aquele contido no voto do ministro Luiz Fux, reafirmando o posicionamento anterior do STF de que não se pode admitir que a 
contribuição sindical seja imposta a trabalhadores e empregadores não sindicalizados, uma vez que a Constituição determina que ninguém é obrigado a se filiar ou a se manter filiado a uma entidade sindical.

A discussão levada ao STF não abrange, contudo, a possibilidade da concessão da autorização prévia ao desconto de forma coletiva, por meio de assembleia convocada nos termos do estatuto da entidade sindical, razão pela qual se justifica a importância de estudo e pesquisa sobre a matéria.

Em 19 de dezembro de $2017^{10}$, o TST homologou Convenção Coletiva de Trabalho entre o Sindicato Nacional das Empresas Aeroviárias (SNEA) e a Federação dos Trabalhadores em Transportes Aéreos. Assim constou da cláusula 53ª do instrumento:

\section{3 - CUSTEIO SINDICAL}

O desconto da contribuição em favor dos sindicatos de trabalhadores, fixado pela assembleia geral da categoria e devidamente registrado em ata, será efetuado em folha de pagamento dos empregados, associados ou não aos Sindicatos, conforme valores e datas fixadas pela assembleia da categoria.

Parágrafo primeiro - A deliberação dos trabalhadores em assembleia será tida como fonte de anuência prévia e expressa dos empregados para efeito de desconto.

Em caso semelhante, o TST homologou termo aditivo ao acordo coletivo de trabalho celebrado entre o Sindicato dos Trabalhadores em Empresas Ferroviárias dos Estados do Maranhão, Pará e Tocantins (STEFEM) e a Vale S. A., prevendo o pagamento de quota negocial pelos empregados.

O acordo coletivo de trabalho originário, celebrado em 28 de novembro de 2017, havia garantido aumento salarial de 2,5\% para os integrantes da categoria, sindicalizados ou não, vale alimentação de $\mathrm{R} \$ 717,50$, adicional noturno de $65 \%$, piso salarial de $\mathrm{R} \$ 1.542,99$ dentre outros benefícios ${ }^{11}$. Posteriormente, em maio de 2018, as partes solicitaram mediação ao TST, para formalizar termo aditivo ao acordo coletivo de trabalho com a previsão de instituição de quota negocial autorizada previamente por assembleia da categoria com esteio na alínea "e" do art. 513 e artigos 611 e seguintes da CLT.

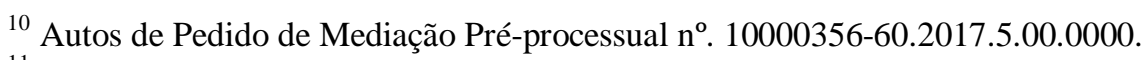

${ }^{11}$ Disponível em: < http://www.tst.jus.br/noticias/-/asset_publisher/89Dk/content/id/24583821 >. Acesso em: 17 jan.2019.
} 
Foi estipulado que a empresa informaria os empregados não sindicalizados a respeito da cobrança para que pudessem exercer seu direito de oposição mediante entrega de carta ao sindicato. A empresa se comprometeu a não fomentar a entrega de cartas de oposição, ao passo que o sindicato se comprometeu a não constranger os empregados não sindicalizados quando da manifestação de seu direito à oposição. Ainda, o sindicato prometeu abster-se de cobrar judicialmente a contribuição prevista no art. 578 e seguintes da CLT bem como a ressarcir a empresa em caso de condenação judicial à devolução de desconto salarial indevido $^{12}$.

Merecem destaque, ainda, recentes iniciativas de sindicatos que ao receber as cartas de oposição ao desconto da contribuição sindical, condicionam o empregado a abrir mão dos benefícios conquistados pela categoria por meio de negociação coletiva ${ }^{13}$.

Ao condicionar o recolhimento da contribuição sindical à autorização prévia e expressa do empregado, a Lei 13.467/2017 alterou significativamente a forma de recolhimento de uma das principais fontes de custeio das entidades sindicais. Os autores do projeto que deu origem à lei defenderam que a facultatividade no recolhimento da contribuição tiraria as entidades sindicais de uma espécie de zona de conforto, estimulando a sobrevivência financeira dos sindicatos que efetivamente engajados na defesa dos interesses da categoria.

Contudo, a nova legislação não esclareceu se a autorização prévia e expressa para o desconto da contribuição sindical poderia ocorrer de forma individual, coletiva ou apenas em uma de tais modalidades. A opção de diversas entidades sindicais em realizar assembleias para deliberar sobre a autorização do desconto da contribuição sindical, conforme autoriza o art. 513 da CLT, provocou relevante debate sobre a legitimidade da via eleita e os alcances de tal deliberação com relação aos empregados não sindicalizados.

De acordo com entendimento de Dias:

Vale assinalar que a legislação modificada não especifica como deve ser colhida a autorização. A nosso sentir, a falta de indicação do formato permite que se reconheça a possibilidade de admitir as várias modalidades autorizativas, inclusive

12 Íntegra do termo aditivo ao acordo coletivo de trabalho disponível em: < https://www.conjur.com.br/dl/aditivo-tst.doc $>$ Acesso em 17 jan.2019.

13 Disponível em: < https://economia.uol.com.br/empregos-e-carreiras/noticias/redacao/2019/01/16/sindicatoscontribuicao-sindical-assistencial-trabalhador-direitos-aumento.htm> Acesso em 17 jan.2019. 
mediante assembleia geral da categoria. Não prevalece, a nosso sentir, a ratio decidendi usada pelo STF na edição da Súmula Vinculante n. 40 e nem em seus precedentes, porquanto ali se trata de outra contribuição, fixada em assembleia. No caso em exame, a contribuição é legalmente fixada, e o que se colhe em assembleia é meramente a autorização para sua cobrança. Logo, entendemos válida autorização individualmente colhida junto ao contribuinte assim como aquela obtida em assembleia geral da categoria, na qual podem participar todos os seus integrantes. (DIAS, FELICIANO, et al., 2018, p. 144)

Conforme exposto, de um lado, o entendimento da ANAMATRA, Ministério do Trabalho e Ministério Público do Trabalho convergiram para a possibilidade de concessão da autorização prévia e expressa mediante assembleia sindical convocada para tal finalidade específica na forma de seu estatuto. De outro, o posicionamento consolidado pelo TST e pelo STF, anteriormente à vigência da Lei 13.467/2017, considerava atentatório ao direito de livre associação e livre sindicalização o estabelecimento de cláusulas de negociação coletiva que instituíssem a cobrança compulsória de contribuições para empregados não sindicalizados.

Ainda assim, conforme crítica de Delgado (2018), já mencionada acima, tal entendimento das Cortes Superiores não se amolda à lógica do sistema constitucional e à melhor interpretação dos princípios da liberdade e autonomia sindical na estrutura da Constituição da República. Acompanhando tal entendimento, as recentes decisões homologatórias de instrumentos de negociação coletiva proferidas pelo TST representam avanço da jurisprudência no sentido de privilegiar as decisões coletivas tomadas em assembleia pela categoria, ainda que se mantenha a possibilidade do exercício individual do direito de oposição.

Contudo, na contramão do entendimento doutrinário e jurisprudencial acima apresentado, em $1^{\circ}$ de março de 2019 foi editada a Medida Provisória 873/2019, que passou a exigir que a autorização para o desconto da contribuição sindical se dê apenas de forma individual. Imperioso, portanto, o debate sobre a constitucionalidade das alterações impostas pela Medida Provisória em comento diante do fim da obrigatoriedade da contribuição sindical e da incômoda manutenção dos pilares da unicidade sindical e da representatividade compulsória.

\section{MEDIDA PROVISÓRIA 873/2019: O FIM DO DEBATE?}


A Medida Provisória 873/2019, publicada no mês em que se descontariam em folha as contribuições sindicais autorizadas previamente pelos trabalhadores, alterou, novamente, a forma de financiamento das entidades sindicais, permitindo o recolhimento da contribuição sindical apenas por parte de trabalhadores sindicalizados ou servidores públicos sindicalizados.

Enquanto a redação dos artigos 578 e 579 da CLT, conferida pela Lei 13.467/2017, apenas exigia que as contribuições sindicais fossem recolhidas desde que prévia e expressamente autorizadas, a Medida Provisória 873/2019 alterou a redação dos dispositivos celetistas para possibilitar o desconto somente mediante autorização prévia, voluntária, individual e expressa. $\mathrm{O} \S 1^{\circ}$ do art. 579 passou a especificar que tal autorização apenas poderia ser feita de forma individual, por escrito, não sendo admitida autorização tácita ou a substituição dos requisitos do caput pela cobrança ainda que oferecido o direito à oposição.

Foi acrescido o art. 579-A à CLT dispondo que apenas podem ser exigidas de empregados filiados ao sindicato a contribuição confederativa de que trata o art. $8^{\circ}$, IV da CF, a mensalidade sindical e demais contribuições sindicais, nelas incluídas aquelas fixadas pelo estatuto do sindicato ou por negociação coletiva.

$\mathrm{O}$ art. 582 CLT passou a autorizar o pagamento da contribuição sindical exclusivamente mediante boleto bancário ou equivalente eletrônico a ser encaminhado obrigatoriamente à residência do empregado ou, na hipótese de impossibilidade de recebimento, à sede da empresa.

Ainda, a Medida Provisória 873/2019 revogou a alínea "c" do caput do art. 240 da Lei 8.112/1990 que autorizava o desconto da mensalidade sindical e contribuições sindicais fixadas em assembleia sindical para os servidores públicos estatutários em âmbito federal.

Em suma, a Medida Provisória 873/2019: i) afastou a obrigação de empregadores, bem como da Administração Pública Federal, de efetuar o desconto de contribuições sindicais em folha de pagamento, excluindo a previsão de pagamento encargos e cominações penais em caso de ausência de repasse da receita das contribuições sindicais aos sindicatos; ii) condicionou o pagamento de contribuições sindicais à autorização prévia, expressa, individual e por escrito do trabalhador, proibindo qualquer forma de autorização tácita para o recolhimento de contribuições sindicais e declarando nula qualquer deliberação coletiva que fixe a compulsoriedade do recolhimento de contribuições sindicais sem os requisitos mencionados, ainda que autorizado em negociação coletiva, assembleia geral ou por outro 
meio previsto no estatuto da entidade; iii) permitiu o recolhimento da contribuição sindical apenas por parte de trabalhadores sindicalizados; iv) determinou que o recolhimento seja feito exclusivamente por boleto bancário ou equivalente eletrônico, a ser encaminhado obrigatoriamente à residência do empregado que tenha concedido autorização prévia, individual, expressa e por escrito em tal sentido; v) estabeleceu que o descumprimento das regras sobre o recolhimento das contribuições sindicais ensejará a aplicação de penalidade administrativas sem prejuízo de ação criminal.

Diante das modificações legais, o custeio das entidades sindicais passa a ser consideravelmente afetado na medida em que se permite o desconto de qualquer espécie de contribuição apenas de trabalhadores sindicalizados, mediante autorização prévia, expressa, por escrito, por boleto bancário a ser enviado à residência do empregado.

Muito embora na exposição de motivos da Medida Provisória 873/2019 tenha se defendido a alteração legislativa com fundamento no princípio da liberdade de associação, autonomia e liberdade sindical, as restrições impostas chocam-se com tais princípios, pois colocam obstáculos que inviabilizam a subsistência financeira de diversas entidades sindicais.

A liberdade sindical consiste no direito de trabalhadores, ou até mesmo empregadores, de constituir e se organizar sindicalmente, da forma como entenderem pertinente, ditando as regras de funcionamento de tais entidades, ações que devam ser empreendidas, tendo liberdade para se associar ou se desassociar e para permanecer voluntariamente associado (BRITO FILHO, 2012, p. 71).

De acordo com o magistério de Arouca (2016, p. 63), a autonomia e a liberdade se completam e dependem do prestígio da autonomia de coletiva de vontades para democratizar as relações de trabalho, consistindo a autonomia em um feixe de liberdades estruturado diante da vontade majoritária de uma coletividade de trabalhadores.

A sensível alteração no sistema de custeio das entidades sindicais em concomitância com a manutenção do enquadramento sindical por categoria pode, portanto, trazer dificuldades ao exercício da liberdade e autonomia sindical. Nesse sentido, Oliveira Neto observa que:

A abrupta supressão da contribuição sindical sem a previsão de outra fonte de custeio implica em risco à liberdade sindical. Ainda que o direito de não se associar seja prestigiado (liberdade sindical negativa), a manutenção de um sistema sindical fundado na unicidade e na representação de toda a categoria requer uma fonte de 
financiamento dos sindicatos, sob pena de inviabilizá-los (OLIVEIRA NETO, 2019, p. 110).

Ao sufocar as receitas financeiras das entidades sindicais, a Medida Provisória 873/2019 dificulta o processo de organização e manifestação da sociedade civil tanto no caso dos trabalhadores celetistas quanto no âmbito dos servidores públicos estatutários federais. Limita-se, deste modo, o exercício do direito de liberdade de associação, de autodeterminação dos cidadãos e de autonomia dos sindicatos que, enquanto entidades associativas, sofrem severa interferência estatal em matéria que deveria ser objeto de deliberação no âmbito coletivo das relações de trabalho.

A Constituição da República garante no caput do art. $8^{\circ}$ a liberdade de associação profissional ou sindical, conferindo ao sindicatos, no inciso III, o dever de defender os interesses coletivos ou individuais de toda categoria, sejam filiados ou não à entidade sindical. Para que tais entidades possam subsistir financeiramente e cumprir ou papel outorgado pela Constituição, o inciso IV prevê que à assembleia geral cabe a fixação de contribuição que, em se tratando de categoria profissional, será descontada em folha para custeio do sistema confederativo, sem prejuízo da contribuição prevista em lei - a contribuição sindical que, antes da vigência da Lei 13.467/2017, tinha natureza compulsória.

É questionável, portanto, a constitucionalidade da Medida Provisória 873/2019, haja vista que a contribuição devida por trabalhadores sindicalizados, destinada ao custeio do sistema confederativo, guarda expressa previsão no texto constitucional quanto ao seu recolhimento mediante desconto em folha de pagamento. Deste modo, condicionar o desconto exclusivamente por meio de boleto bancário ou equivalente eletrônico afronta a literalidade do texto constitucional. Noutras palavras, condicionar o recolhimento de contribuições sindicais à autorização prévia, expressa, individual, formalizada por escrito e mediante boleto bancário denota clara interveniência estatal indevida na autonomia das entidades sindicais.

Ao dispor sobre os direitos e garantias individuais, os incisos XVII e XVIII do art. $5^{\circ}$ da Carta Republicana asseguram o direito de liberdade de associação e a criação de associações independentemente da autorização estatal, sendo vedada a interferência estatal no seu funcionamento - vedação que se repete, especificamente quanto às entidades associativas sindicais no inciso I do art. $8^{\circ}$ da Constituição da República. Sob a luz da hermenêutica constitucional, o ato de se filiar voluntariamente a uma determinada entidade sindical, concordando com o pagamento de mensalidades ou outras contribuições em folha de 
pagamento, configura legítimo exercício de um direito individual do cidadão que resta obstaculizado pela Medida Provisória 873/2019.

O mais recente óbice legislativo criado contraria, ainda, o entendimento do Comitê de Liberdade Sindical da OIT citado no item anterior do presente trabalho. Conforme decisões do referido órgão internacional, devem ser evitadas as proibições do desconto em folha que possam causar dificuldades financeiras para organizações sindicais, sendo preferível que a questão do desconto de contribuições sindicais ser resolvida pela negociação coletiva e sem obstáculos de natureza legislativa ${ }^{14}$.

Pode-se concluir, portanto, que a Medida Provisória 873/2019, além de contrariar o entendimento do Comitê de Liberdade Sindical da OIT, afronta a literalidade do texto constitucional por atentar contra os princípios da liberdade e autonomia sindical, sem prejuízo de outras violações ao texto constitucional tal como defendido pelo Conselho Federal da OAB na Ação Direta de Inconstitucionalidade de $\mathrm{n}^{\mathrm{o}}$. $6.098^{15}$.

Com o fim da compulsoriedade da contribuição sindical e, agora, com as novas restrições impostas ao recolhimento da contribuição, ao contrário de estimular novas filiações e fomentar a representação mais efetiva das categorias profissionais, a tendência é o enfraquecimento das entidades sindicais. Conforme aponta Oliveira Neto (2019, p. 115), a impossibilidade de escolha de sindicato, decorrente da unidade sindical, e a eficácia erga omnes dos instrumentos de negociação coletiva, independentemente de filiação, desestimulam o associativismo sindical e geram sensação de indiferença ao trabalhador dentro de um

\footnotetext{
${ }^{14}$ Nesse sentido as decisões de $n^{\circ} .474$ e 481 do ementário do Comitê de Liberdade Sindical da OIT citado no Item 2 do presente trabalho.

${ }^{15}$ Conforme decisão proferida pelo Min. Luiz Fux, em síntese, o Conselho Federal da OAB alega: "(i) que não estariam presentes os requisitos da relevância e da urgência para a edição da Medida Provisória atacada; (ii) que medida provisória não poderia disciplinar direitos decorrentes da cidadania; (iii) que a vedação ao desconto em folha de pagamento das mensalidades e contribuições devidas aos sindicatos teria implicado ofensa à liberdade de associação; (iv) que as mensalidades devidas pelos associados às entidades sindicais, sob a forma de contribuição para custeio do sistema confederativo, são fixadas pelas assembleias gerais e descontadas em folha, nos termos do artigo $8^{\circ}$, IV, da Constituição Federal, não cabendo ao legislador infraconstitucional dispor de modo diverso; (v) que teria havido ofensa ao ato jurídico perfeito ao se desconsiderar as manifestações pretéritas dos trabalhadores, tácitas ou expressas, autorizando o desconto em folha das contribuições sindicais; (vi) que a exigência de autorização prévia, voluntária, individual, expressa e escrita para a cobrança das contribuições sindicais, bem como a imposição da utilização de boleto bancário, seriam ofensivas à autonomia sindical e à negociação coletiva como forma privilegiada para a solução de conflitos laborais; e (vii) que a imposição dos referidos entraves ao recolhimento das contribuições devidas às entidades sindicais afrontaria os princípios da proporcionalidade e da vedação ao retrocesso social." Disponível em: < http://portal.stf.jus.br/processos/detalhe.asp?incidente=5649469 >. Acesso em 04 abr.2019.
} 
sistema em que a legitimidade de representação da categoria é outorgada artificialmente a uma única entidade sindical.

Mostra-se necessária, portanto, a revisão do modelo sindical adotado no Brasil a fim de que sejam salvaguardados os princípios da liberdade e autonomia sindical.

\section{CONSIDERAÇÕES FINAIS}

Ao condicionar o recolhimento da contribuição sindical à autorização prévia e expressa do empregado, a Lei 13.467/2017 alterou significativamente a forma de recolhimento de uma das principais fontes de custeio das entidades sindicais. Os autores do projeto que deu origem à lei defenderam que a facultatividade no recolhimento da contribuição tiraria as entidades sindicais de uma espécie de zona de conforto, estimulando a sobrevivência financeira dos sindicatos que efetivamente engajados na defesa dos interesses da categoria.

Contudo, a nova legislação não esclareceu se a autorização prévia e expressa para o desconto da contribuição sindical poderia ocorrer de forma individual, coletiva ou apenas em uma de tais modalidades. A opção por realizar assembleias para deliberar sobre a autorização do desconto da contribuição sindical, conforme preconiza o art. 513 da CLT, provocou relevante debate sobre a legitimidade da via eleita e os alcances de tal deliberação com relação aos empregados não sindicalizados.

De um lado, o entendimento da ANAMATRA, MTE e MPT convergiram para a possibilidade de concessão da autorização prévia e expressa mediante assembleia sindical convocada para tal finalidade específica na forma de seu estatuto. De outro, o posicionamento consolidado pelo TST e pelo STF, anteriormente à vigência da Lei 13.467/2017, considerava atentatório ao direito de livre associação e livre sindicalização o estabelecimento de cláusulas de negociação coletiva que instituíssem a cobrança compulsória de contribuições para empregados não sindicalizados.

De todo modo, conforme crítica de Delgado, tal entendimento das Cortes Superiores não se amolda à lógica do sistema constitucional e à melhor interpretação dos princípios da liberdade e autonomia sindical na estrutura da Constituição Federal. Acompanhando tal entendimento, as recentes decisões homologatórias de instrumentos de negociação coletiva 
proferidas pelo TST representam avanço da jurisprudência no sentido de privilegiar as decisões coletivas tomadas em assembleia pela categoria.

Em análise aos sistemas de custeio de entidades sindicais de outros países e, ao se debruçar sobre decisões proferidas pela OIT sobre a matéria, pode-se concluir que a autorização prévia e expressa outorgada de forma coletiva, com amparo no art. 513, "e" da CLT, com garantia de direito à oposição, não seria atentatória aos princípios da liberdade sindical e liberdade de associação quando toda a categoria, sindicalizada ou não, é beneficiada pelos instrumentos de negociação coletiva e recebe assistência sindical.

As deliberações coletivas homologadas pelo TST acompanham, portanto, o entendimento da OIT sobre o tema, valorizando a coletividade beneficiada pelo instrumento negocial e contribuindo para a construção de uma sociedade livre, justa e solidária.

No entanto, a Medida Provisória 873/2019 veio de encontro com tais entendimentos, ao restringir o recolhimento da contribuição sindical à autorização prévia, expressa, individual, por escrito, mediante boleto bancário e somente dos trabalhadores sindicalizados. Muito embora tenha se defendido a alteração legislativa com fundamento no princípio da liberdade de associação, autonomia e liberdade sindical, as restrições impostas chocam-se com tais princípios, pois colocam obstáculos que inviabilizam a subsistência financeira de diversas entidades sindicais, razão pela qual conclui-se pela inconstitucionalidade da Medida Provisória.

\section{BIBLIOGRAFIA}

ANAMATRA. Associação Nacional dos Magistrados do Trabalho. Enunciados da $\mathbf{2}^{\mathbf{a}}$ Jornada de Direito Material e Processual do Trabalho, 2017. Disponivel em: <http://www.jornadanacional.com.br/listagem-enunciados-aprovados-vis1.asp>. Acesso em: 16 jan. 2019.

AROUCA, J. C. Curso Básico de Direito Sindical. 5a . ed. São Paulo: LTr, 2016.

BRASIL. Câmara dos Deputados. Relatório da Comissão Especial destinada a proferir parecer ao projeto de lei 6.787 de 2016 que altera a CLT, 2017. Disponivel em: <http://www.camara.gov.br/proposicoesWeb/prop_mostrarintegra?codteor=1544961>. Acesso em: 16 jan. 2019. 
BRITO FILHO, J. C. M. Direito Sindical: Análise do Modelo Brasileiro de Relações Coletivas do Trabalho à Luz do Direito Estrangeiro Comparado e da Doutrina da OIT Proposta de Inserção da Comissão de Empresa. 4ª ed. São Paulo: LTr, 2012.

DELGADO, M. G. Curso de Direito do Trabalho. 17ª ed. São Paulo: LTr, 2018.

DIAS, C. E. O. et al. Comentários à Lei da Reforma Trabalhista: Dogmática, Visão Vrítica e Interpretação Constitucional. 1 a . ed. São Paulo: LTr, 2018.

LACERDA, C. C. Nota Técnica no . 02/2018/GAB/SRT. Ministério do Trabalho e Emprego. Brasília. 2018.

MARTINS, I. G. D. S. A contribuição sindical e sua natureza jurídica. Revista do Tribunal Superior do Trabalho, São Paulo, v. 81, p. 88-106, abr/jun 2015.

MARTINS, S. P. Contribuições sindicais, direito comparado e internacional, contribuições assistencial, confederativa e sindical. São Paulo: Atlas, 2009.

NASCIMENTO, A. M.; NASCIMENTO, S. M.; NASCIMENTO, M. M. Compêndio de

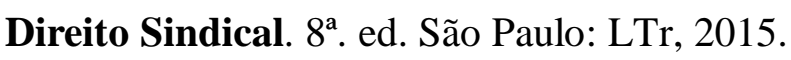

OIT. Direito Coletivo, a liberdade sindical e as normas internacionais. Tradução de Sandro Lunard NICOLADELI e Tatyana Scheila FRIEDERICH. São Paulo: LTr, v. II, 2013.

OLIVEIRA NETO, A. E. D. Contribuições sindicais: modalidades de financiamento sindical e o princípio da liberdade sindical de acordo com a Lei 13.467/2017. 2a . ed. São Paulo: LTr, 2019.

PEGO, R. F. Fundamentos do Direito Coletivo do Trabalho e o Paradigma da Estrutura Sindical Brasileira. $1^{\text {a }}$. ed. Porto Alegre: Livraria do Advogado. Amazon e-book Kindle., 2012.

SANTOS, E. R. Fundamentos do Direito Coletivo do Trabalho nos Estados Unidos, na União Europeia, no Mercosul e a Experiência Sindical Brasileira. $2^{\text {a }}$. ed. Rio de Janeiro: Lumen Juris, 2018.

VAlentim, J. H.; OliVeirA NeTO, A. E. D. Nota Técnica $\mathbf{n}^{\mathbf{}} .01$ de 27 de abril de 2018. Ministério Público do Trabalho. Brasília. 2018. 